\title{
Effectiveness of near-peer simulation for managing the acutely deteriorating patient among residents of an internal medicine junior residency programme
}

\author{
Xiayan $\underline{S h e n}^{1}$, MBBS, Benjamin Wei Rong $\underline{T a y}^{1}$, MBBS, Benjamin Yong-Qiang $\underline{T a n}^{1}$, MBBS, Nicholas Jinghao $\underline{\text { Ngiam }}^{1}$, MBBS, \\ John Shao Rong $\underline{M_{0 k}^{1}}$, MBBS, Shao Feng $\underline{M o k^{1}}$, MBBS, Eng Soo $\underline{\text { Yap }}^{2}$, MBBS, See Meng $\underline{\text { Khoo }^{1,3}}$, MBBS
}

\begin{abstract}
INTRODUCTION Near-peer teaching is gaining popularity as a teaching modality, as it improves the learner's understanding, is targeted at an appropriate level and promotes familiarisation. This study was initiated to evaluate the effectiveness of incorporating near-peer instruction into simulation-based training within a junior residency programme.

METHODS 42 first-year residents from an internal medicine junior residency programme were recruited. Participants underwent a simulation-based training programme conducted over five weeks. Each week involved either an emergency or acute clinical scenario. A structured questionnaire was administered prior to and after the course to compare participants' perceived knowledge, experience and confidence in managing the clinical scenarios.

RESULTS In our study, $83 \%$ of participants agreed/strongly agreed that the scenarios were realistic. There were improvements in perceived knowledge, experience and confidence after the course. The greatest improvement was seen for experience (post-simulation: median 7.00 [interquartile range (IQR) 6.00-8.00] vs. pre-simulation: median 5.00 [IQR 3.00-6.25]). $65 \%$ of participants were keen to help with future training.

CONCLUSION Near-peer simulation training was found to be a viable and valuable method of instruction for firstyear residents for increasing experience, instilling confidence and improving perceived knowledge. Integration of such programmes within medical education curricula shows good promise of continuity, with many first-year residents inspired to organise subsequent sessions.
\end{abstract}

Keywords: junior residents, medical education, near-peer teaching, residency programme, simulation

\section{INTRODUCTION}

The advent of international accreditation has revolutionised postgraduate medical education worldwide. Likewise, Singapore's training landscape was transformed following the introduction of a residency programme under the Accreditation Council for Graduate Medical Education-International (ACGME-I) standards in 2009. Under this new programme, the existing medical curriculum has been streamlined and condensed, reducing the time required for completion of speciality-specific postgraduate training. ${ }^{(1-3)}$ This reduction in training duration meant that residents are required to acquire important skills used in the management of acutely unwell patients within an abridged time frame.

Historically, full-body mannequins were best suited for anaesthesia and advanced cardiac life support scenarios. ${ }^{(4,5)}$ As internal medicine training heavily involves diagnostic skills, simulation scenarios in internal medicine are best done with additional layers, such as obtaining a history using an embedded microphone in the mannequin. Simulation scenarios can be scripted to reproduce complex situations, including diagnostic and management dilemmas, and are ideal for team training. Well-scripted simulation in internal medicine may even provide trainees with cues and consequences similar to real-life situations encountered in the hospital. ${ }^{(6)}$ Such high-fidelity simulation provides an opportunity to compress the learning time in medicine through a high-quality experiential learning environment. ${ }^{(7)}$ The curriculum can be taught in a reproducible and emotionally engaging manner that significantly enhances understanding and retention, and reduces knowledge gaps in knowledge and skills. ${ }^{(4)}$ A high-fidelity simulation programme can reproducibly teach and assess most, if not all, of the ACGME competencies under direct observation. Patient safety issues can be simulated and practised, so that mastery of skills occurs in a safe environment. ${ }^{(8)}$ Mistakes can occur without 'real-life' consequences. High-fidelity patient simulation has been described as a method to not only teach but also evaluate while replicating a variety of clinical encounters. ${ }^{(9-12)}$ Such programmes are commonly facilitated by faculty experts. However, there has been increasing interest and research in the near-peer approach. ${ }^{(13)}$

Near-peer teaching is a peer-assisted learning technique that has gained increased acceptance over the past decade. Evidence suggests that in medical education, this technique benefits students, teachers and even medical institutions. ${ }^{(14,15)}$ A near-peer teacher is defined as a trainee who is one or more years senior to another trainee at the same level of medical education training. ${ }^{(16)}$ Near-peer teachers are neither professional educators nor experts in a given field; they teach their peers or junior learners while they themselves continue to learn. ${ }^{(17)}$ Both tutors and learners are usually of similar educational maturity and social standing,

${ }^{1}$ Department of Medicine, National University Health System, ${ }^{2}$ Department of Laboratory Medicine, National University Hospital, ${ }^{3}$ Yong Loo Lin School of Medicine, National University of Singapore, Singapore

Correspondence: Dr Benjamin Yong-Qiang Tan, Senior Resident, Division of Neurology, Department of Medicine, National University Health System, 1 E Kent Ridge Road, NUHS Tower Block, Singapore 119228. benjamin_yq_tan@nuhs.edu.sg 
which cultivates a shared level of understanding. ${ }^{(18,19)}$ Therefore, peer teachers are able to appreciate their learner's needs, anticipate their pitfalls and facilitate easy transfer of experience and knowledge in an unintimidating learning environment. ${ }^{(13,20,21}$

The short training duration mandates the need to achieve effective learning quickly. Therefore, it is crucial to incorporate a module that combines the most effective and efficient methods of delivery. We hypothesised that a learning module that combines simulation and near-peer teaching to teach emergency algorithmdriven management would enhance the learners' confidence, experience and perceived knowledge.

\section{METHODS}

This was a prospective study conducted in a tertiary academic healthcare institution in Singapore and comprised five one-hour sessions held weekly over five consecutive weeks. Overall, 42 first-year residents were enrolled into the study over two study periods conducted from January 2016 to February 2016 and from May 2016 to June 2016. Data was collected via questionnaires administered prior to the start and at the end of each study period. Ethics approval to conduct the study was obtained from the local institution review board. Individual participant consent was also obtained.

The second-year residents involved in conducting the near-peer simulation underwent a two-day Simulation Faculty Development Workshop conducted by the Centre for Healthcare Simulation, NUS Yong Loo Lin School of Medicine, National University of Singapore, Singapore, prior to the start of the nearpeer simulation programme. Core skills, such as developing and evaluating a simulation-based programme, as well as debriefing and feedback techniques, were taught during the workshop.

Upon completion of the Simulation Faculty Development Workshop, simulation scenarios were planned by the second-year residents after consultation with senior residents (specialists-intraining) from the relevant specialities before the final framework was vetted by a specialist. The scenarios were selected to recreate the most common acute clinical situations faced by residents. These included: (a) acute myocardial infarction; (b) unstable atrial fibrillation with acute pulmonary oedema; (c) acute gastrointestinal bleeding; (d) blood transfusion reaction or transfusion-associated acute lung injury; and (e) severe pneumonia. Each scenario was centred on a predefined set of learning objectives, which included clinical content, clinical decision-making, and procedural and communication skills (Appendix 1). Facilitators rehearsed the scenarios in the presence of senior residents before being permitted to run the near-peer sessions.

First-year residents were given protected curriculum time to participate in the simulation sessions to enhance concentration and learning during the simulation sessions. ${ }^{(22)}$ Orientation to the simulator and emergency equipment was provided prior to the start of the programme. Each clinical encounter lasted for half an hour and involved a group of four residents, with one of them being assigned as a team leader. To maximise learning and time in accordance to previous studies, residents not participating in the scenario observed the encounter via live video feed in a separate room $^{(23)}$ and later provided peer feedback to the participants following the end of the simulation scenario. A second-year resident, supervised by a senior resident, conducted the scenario.

Participants were provided with a clinical stem on entry to the scenario. Facilitators provided a standardised history while positioned in an adjacent room, which had a one-way mirror to allow visual supervision of the simulation session. Physical and vital signs were simulated using high-fidelity mannequins (Laerdal SimMan 3G; Laerdal Medical, Stavanger, Norway), which concurrently allowed assessment of procedural skills. Evolution of the scenario was based on participants completing predefined management tasks and satisfactory demonstration of procedural skills. Each scenario concluded with a formal handover of the patient to the facilitators (Appendix 2).

Debriefing was conducted immediately after the simulation encounter. Emphasis was placed on providing a supportive learning environment, with objective indicators of performance. ${ }^{(22)}$ Participants were first encouraged to reflect on their own performance before a review by their fellow peers. Priority of self- and peer-reflection was placed on domains such as communication, teamwork interactions, role clarity and situational awareness, in addition to areas for improvement. ${ }^{(24-26)}$

Thereafter, second-year resident facilitators critiqued the residents' performance in accordance to the Pendleton's Model (taught at the Simulation Faculty Development Workshop), with a diagnostic evaluation of positive and negative events occurring during the encounter. The facilitator reinforced what was done well to the participant and gave advice on how the scenario could have been improved based on hospital treatment protocols and systems-based best practices. ${ }^{(27)}$ The senior resident was then invited to provide a summary of evidence-based management and address content-specific questions raised by participants. An action plan for improvement was made at the end of each debriefing session.

Participants were assessed via a previously published selfreported questionnaire (Appendix 3). ${ }^{(28)}$ It comprised a paired pre-post ten-point Likert scale assessment across three domains of knowledge, experience and confidence in managing critically ill patients. A free-text section was included to facilitate qualitative analysis on the aforementioned three domains. Participants were also tasked to rank their top five concerns, out of a selection of 11, pertaining to management of the critically ill patient before and after the simulation. Non-paired questions were also included in the questionnaire. These assessed participants' attitude towards a team-based approach to patient care.

In addition to these standard questions in the previously published questionnaire, participants were also asked to provide their views on the strengths and weaknesses of simulation-based training, and their willingness to help run simulation training sessions for future residents via a five-point Likert scale, with 1 being 'strongly disagree' and 5 being 'strongly agree'.

Non-parametric paired Likert scale data was collected pre- and post-simulation and compared using the Wilcoxon signed rank test, with $p<0.05$ considered to be statistically significant. Ranked concerns were reflected as mean values, while 


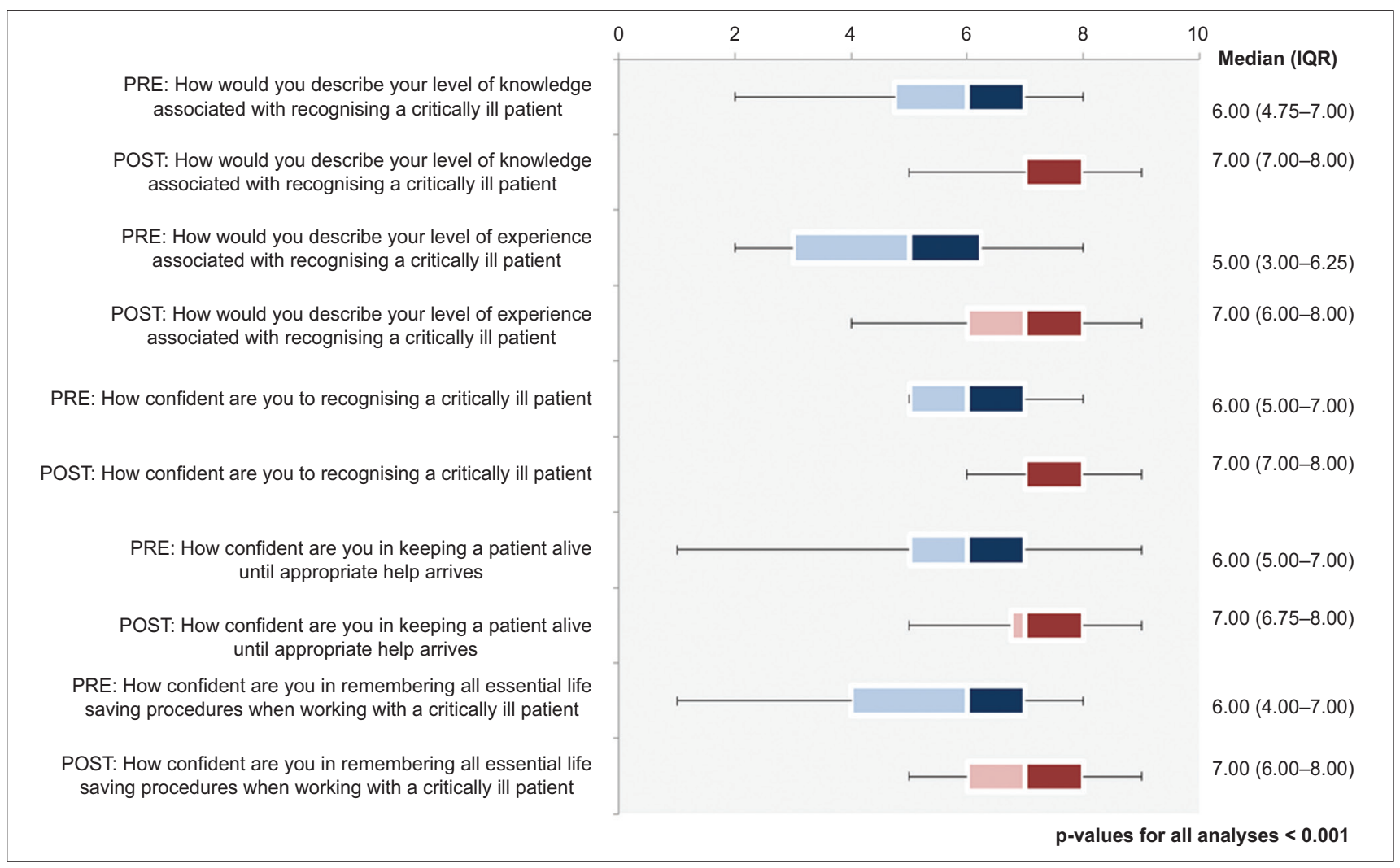

Fig. 1 Box and whisker plot shows paired analysis of participants' knowledge, experience and confidence pre- and post-simulation. Note: $p<0.001$ for all analyses. IQR: interquartile range; POST: post-simulation; PRE: pre-simulation

non-paired results were reflected as percentages. All statistical analyses were performed using IBM SPSS Statistics for Windows version 20.0 (IBM Corp, Armonk, NY, USA).

\section{RESULTS}

None of our participants were exposed to simulation-based training as a qualified doctor. However, $93 \%$ of participants had experienced simulation-based training in medical school during their undergraduate training.

Prior to our training programme, the domain with the lowest ten-point Likert score was that of experience in recognising an emergency scenario (median 5.00 [interquartile range (IQR) $3.00-6.25]$ ). Participants were also less confident in being able to remember the necessary steps and information in an emergency situation (median 6.00 [IQR 4.00-7.00]) (Fig. 1).

Improvements in Likert scores from all three domains were observed among participants after completion of the programme. These were found to be statistically significant $(p<0.001)$. The greatest improvement was appreciated in the domain of experience (post-simulation: median 7.00 [IQR 6.00-8.00] vs. pre-simulation: median 5.00 [IQR 3.00-6.25]), followed by knowledge (post-simulation: median 7.00 [IQR 7.00-8.00] vs. pre-simulation: median 6.00 [IQR 4.75-7.00]) and confidence (post-simulation: median 7.00 [IQR 7.00-8.00] vs. pre-simulation: median 6.00 [IQR 5.00-7.00]) for managing critically ill patients.

Analysis of participants' ranking of concerns (Table I) showed that the top concerns before starting the simulation was the rapid deterioration of critically ill patients (mean rank 3.05) as well as the lack of experience in managing such patients (mean rank 2.73). Following the simulation, the top three concerns of participants remained the same, although participants were now more concerned regarding their lack of prior experience (mean rank 2.76) and were less concerned about the rapid deterioration of their patients (mean rank 2.63). Residents also realised the need to keep calm during the management of acutely unwell patients, which became their fifth concern post simulation, up from the tenth rank pre-simulation.

With regard to high-fidelity simulation as a training medium, $83 \%$ of participants agreed/strongly agreed that the scenarios were an accurate reflection of real-life situations, with a further $90 \%$ agreeing that the scenarios had good learning value. A majority $(86 \%)$ of participants agreed that simulation-based teaching was preferable to didactic sessions for better conveying lessons on management of emergency and acute clinical scenarios. Some qualitative comments from the participants included the following: "Hands-on exposure, practical tips. Good exposure and learning! Good bite-sized learning, can learn and remember, when there is not too much information at one go"; $^{\prime \prime}$ and "Simulation helps practice prioritising manpower, running the steps of airway/breathing/circulation, handover". Finally, $65 \%$ of participants agreed that they would be keen to help with the planning and execution of future simulation-based training sessions for their juniors.

In terms of the facilitators, qualitative comments collated included the following: "Refreshed my own knowledge about the subject matter and, along the way, gleaned in-depth knowledge 
Table I. Ranked concerns before and after the near-peer-led simulation programme.

\begin{tabular}{|c|c|c|c|}
\hline \multicolumn{4}{|c|}{ Mean rank of concerns when dealing with a critically ill patient } \\
\hline \multicolumn{2}{|l|}{ Pre-simulation } & \multicolumn{2}{|l|}{ Post-simulation } \\
\hline Concern & Rank & Concern & Rank \\
\hline Rapid deterioration & 3.05 & Lack of prior specific experience & 2.76 \\
\hline Lack of prior specific experience & 2.73 & Rapid deterioration & 2.63 \\
\hline Applying skills in real-life setting & 1.62 & Applying skills in real-life setting & 2.10 \\
\hline Lack of competence & 1.27 & Lack of competence & 1.46 \\
\hline Taking too long to react & 1.24 & Keeping calm & 1.29 \\
\hline Unable to get help when needed & 1.15 & Lack of knowledge & 1.20 \\
\hline Lack of knowledge & 1.13 & Lack of diagnosis & 1.15 \\
\hline Lack of diagnosis & 1.05 & Remembering to conduct all appropriate investigations & 0.78 \\
\hline Finding specific procedure/actions difficult & 0.68 & Taking too long to react & 0.78 \\
\hline Keeping calm & 0.59 & Finding specific procedure/actions difficult & 0.46 \\
\hline $\begin{array}{l}\text { Remembering to conduct all appropriate } \\
\text { investigations }\end{array}$ & 0.21 & Unable to get help when needed & 0.44 \\
\hline
\end{tabular}

while preparing for the teaching session"; and "Learned the importance of debriefing and improved my own debriefing skills through running the simulation programme".

\section{DISCUSSION}

Our study showed that a simulation programme for first-year residents had improved their perceived knowledge, experience and confidence towards acute clinical scenarios. This is in keeping with the results of a previous resident-led medical simulation curriculum in a large internal medicine residency programme. ${ }^{(29}$

It may be argued that any teaching intervention will be more effective at developing learners' skills or knowledge than no intervention, and thus the positive results of non-comparative pre- and post-studies of peer teaching are unsurprising. The significant gains in self-reported experience, as compared to their self-perceived improvement in knowledge, and confidence in managing and keeping critically ill patients alive, may be a reflection of the fact that the greatest value of near-peer simulation teaching is in improving experience and it is less effective in imparting knowledge and confidence.

Simulation is a technique used to replace or amplify real experiences using guided experiences that evoke or replicate substantial aspects of the real world in a fully interactive manner. ${ }^{30}$ Multiple studies have compared non-simulation-based teaching methods with simulation-based medical education, ${ }^{(31-35)}$ revealing small-to-moderate positive effects for simulation. ${ }^{(31)}$ Furthermore, recent changes towards work-hour restrictions for residents, and an increased commitment to patient safety have limited the opportunities for patient encounters and thus constitute a strong argument for simulation-based training. ${ }^{(12,36,37)}$

The concept of near-peer teaching is founded on the elements of cognitive and social congruence. Cognitive congruence refers to the similarity of tutor and student in intellect and thoughtprocessing. Within peer teaching, both learners and teachers are of a similar level educationally, leading to greater cognitive congruence compared to faculty-led teaching. This allows peer teachers to express often complex and intimidating topics in ways that learners are better able to understand. ${ }^{(18)}$ Furthermore, peer teachers themselves will have recently covered the same material and may be able to express the concepts in a manner to which novices are more receptive. Similarly, peer learners and peer teachers are expected to be of the same or a comparable social standing. As a result of this social congruence, peer teachers seem to express more of an understanding of their learner's needs and concerns, by way of an increased understanding of their own social and academic lives. ${ }^{(19)}$

Near-peer teaching allowed residents to feel at ease to ask questions when they had doubts, and perceive that the facilitators were able to understand their needs and address their concerns. ${ }^{(38)}$ Near-peer facilitators were able to share their working experiences and explain hospital treatment protocols while relating to these newly qualified doctors during the simulation programme, which may further add value to previous studies that show that simulation-based training increases compliance to hospital cardiac resuscitation protocols. ${ }^{(27)}$ Similarly, the facilitators from the course expressed that in aiding the junior residents in their simulationbased scenario, they too benefited and gained new insights and teaching skills in the process. These were consistent with sentiments expressed by near-peer tutors and students in previous studies. ${ }^{(16)}$

A similar programme was conducted in an internal medicine residency programme in North America. This was a pilot study held at the Massachusetts General Hospital and it demonstrated the practicability of resident-led simulation training. ${ }^{(29)}$ Our study supports the reproducibility of these findings in the Asian context. A majority of our participants also reflected an interest in contributing to the continuation of the project, thus ensuring sustainability to such an endeavour. Furthermore, our study revealed additional benefits of such programmes vis-à-vis confidence building, which is of particular significance in the Asian context, whereby a cultural mindset, revolving around the belief that the 'doctor knows what is best', esteems the confident, decisive clinician. ${ }^{(39,40)}$

This study was not without limitations. It was limited to a small cohort of 42 first-year residents. A randomised controlled 
trial, where all participants underwent the simulation-based training, with a control group of participants undergoing conventional didactic sessions or other methods of instruction, would be useful to compare the effectiveness of the programme. Similarly, the actual proficiency of each candidate was also not objectively assessed. Instead, we compared the individual participant's perceived knowledge, experience and confidence with regard to the clinical scenario. The focus of our study was not to compare simulation-based training to didactic sessions, but to demonstrate the former as a viable method of instruction for teaching emergency and acute clinical scenarios. Further studies may be warranted to measure actual differences in clinical competency using the simulation-based teaching method when compared to other teaching methods.

In conclusion, our experience shows that it may be beneficial for residency programmes to conduct a simulation-based medical education programme for first-year residents, specifically to aid residents in preparing to face real-life emergency scenarios. Nearpeer simulation training was found to be both viable as well as valuable as a method of instruction for teaching first-year residents and cultivating knowledge, increasing experience and instilling confidence, especially in the context of acute and emergency clinical scenarios. Furthermore, such a programme shows good promise of continuity, as many first-year residents have been inspired to plan and organise subsequent sessions in the future to help their juniors.

\section{ACKNOWLEDGEMENTS}

We would like to acknowledge Ms Jasmine Tze Yin Ho, National University Hospital (NUH), Singapore, for her assistance in coordinating the simulation sessions and providing logistic support. The authors would also like to express our heartfelt gratitude to all consultants and senior residents from NUH who were involved in this programme, including Dr Calvin Koh, Dr Tan Liling, Dr Tan Liwei, Dr Serene Wong, Dr Siow Wen Ting, Dr Liew Mei Fong, Dr Deanna Lee, Dr Liesel Fong and Dr Wang Kangjie.

\section{SUPPLEMENTARY MATERIAL}

Appendices 1-3 are available online at https://doi.org/10.11622/ smedj. 2019056.

\section{REFERENCES}

1. Accreditation Council for Graduate Medical Education International. ACGME-I Mission. Available at: http://www.acgme-i.org/About-Us/Mission. Accessed December 4, 2016.

2. Ministry of Health Holdings, Singapore. About Residency. Available at: http:// www.physician.mohh.com.sg/residency/about_residency.html. Accessed December 4, 2016.

3. Samarasekera DD, Ooi S, Yeo SP, Hooi SC. Medical education in Singapore. Med Teach 2015; 37:707-13.

4. Simulation as a Teaching Tool. Available at: https://harvardmedsim.org/course/ simulation-as-a-teaching-tool/. Accessed January 20, 2018.

5. Lateef F. Simulation-based learning: just like the real thing. J Emerg Trauma Shock 2010; 3:348-52.

6. Ogden PE, Cobbs LS, Howell MR, Sibbitt SJ, DiPette DJ. Clinical simulation: importance to the internal medicine educational mission. Am J Med 2007; 120:820-4.

7. Gordon JA, Oriol NE, Cooper JB. Bringing good teaching cases "to life": a simulator-based medical education service. Acad Med 2004; 79:23-7.

8. Pothiawala S, Lateef F. Simulation training in emergency medicine (STEM): an integral component of residency curriculum. Hong Kong J Emerg Med 2012; 19:41-5.

9. Kneebone RL, Scott W, Darzi A, Horrocks M. Simulation and clinical practice: strengthening the relationship. Med Educ 2004; 38:1095-102.

10. McLaughlin SA, Doezema D, Sklar DP. Human simulation in emergency medicine training: a model curriculum. Acad Emerg Med 2002; 9:1310-8.

11. McMahon GT, Monaghan C, Falchuk K, Gordon JA, Alexander EK. A simulatorbased curriculum to promote comparative and reflective analysis in an internal medicine clerkship. Acad Med 2005; 80:84-9.

12. Vozenilek J, Huff JS, Reznek M, Gordon JA. See one, do one, teach one: advanced technology in medical education. Acad Emerg Med 2004; 11:1149-54.

13. Ten Cate O, Durning S. Peer teaching in medical education: twelve reasons to move from theory to practice. Med Teach 2007; 29:591-9.

14. Burgess A, McGregor D, Mellis C. Medical students as peer tutors: a systematic review. BMC Med Educ 2014; 14:115.

15. Yu TC, Wilson NC, Singh PP, et al. Medical students-as-teachers: a systematic review of peer-assisted teaching during medical school. Adv Med Educ Pract $2011 ; 2: 157-72$.

16. Bulte C, Betts A, Garner K, Durning S. Student teaching: views of student nearpeer teachers and learners. Med Teach 2007; 29:583-90.

17. Ross MT, Cameron HS. Peer assisted learning: a planning and implementation framework: AMEE Guide no. 30. Med Teach 2007; 29:527-45.

18. Lockspeiser TM, O'Sullivan P, Teherani A, Muller J. Understanding the experience of being taught by peers: the value of social and cognitive congruence. Adv Health Sci Educ Theory Pract 2008; 13:361-72.

19. Schmidt HG, Moust JH. What makes a tutor effective? A structural-equations modeling approach to learning in problem-based curricula. Acad Med 1995; 70:708-14.

20. Cash T, Brand E, Wong E, et al. Near-peer medical student simulation training. Clin Teach 2017; 14:175-9.

21. Epstein RM. Assessment in medical education. N Engl J Med 2007; 356:387-96.

22. McGaghie WC, Issenberg SB, Petrusa ER, Scalese RJ. A critical review of simulationbased medical education research: 2003-2009. Med Educ 2010; 44:50-63.

23. Wulf G, Shea C, Lewthwaite R. Motor skill learning and performance: a review of influential factors. Med Educ 2010; 44:75-84.

24. Krogh CL, Ringsted C, Kromann CB, et al. Effect of engaging trainees by assessing peer performance: a randomised controlled trial using simulated patient scenarios. Biomed Res Int 2014; 2014:610591.

25. Salas E, Klein C, King H, et al. Debriefing medical teams: 12 evidence-based best practices and tips. Jt Comm J Qual Patient Saf 2008; 34:518-27.

26. Sorbero ME, Farley DO, Soeren M, Lovejoy SL. Outcome Measures for Effective Teamwork in Inpatient Care: Final Report. Available at: https://www.rand.org/ ubs/technical_reports/TR462.html. Accessed December 13, 2019.

27. Wayne DB, Didwania A, Feinglass J, et al. Simulation-based education improves quality of care during cardiac arrest team responses at an academic teaching hospital: a case-control study. Chest 2008; 133:56-61.

28. Featherstone P, Smith GB, Linnell M, Easton S, Osgood VM. Impact of a oneday inter-professional course (ALERT) on attitudes and confidence in managing critically ill adult patients. Resuscitation 2005; 65:329-36.

29. Mathai SK, Miloslavsky EM, Contreras-Valdes FM, et al. How we implemented a resident-led medical simulation curriculum in a large internal medicine residency program. Med Teach 2014; 36:279-83.

30. Gaba DM. The future vision of simulation in health care. Qual Saf Health Care 2004; 13 Suppl 1:i2-10.

31. Cook DA, Brydges R, Hamstra SJ, et al. Comparative effectiveness of technologyenhanced simulation versus other instructional methods: a systematic review and meta-analysis. Simul Healthc 2012; 7:308-20.

32. Gordon JA, Shaffer DW, Raemer DB, et al. A randomized controlled trial of simulation-based teaching versus traditional instruction in medicine: a pilot study among clinical medical students. Adv Health Sci Educ Theory Pract 2006; 11:33-9.

33. Lo BM, Devine AS, Evans DP, et al. Comparison of traditional versus high-fidelity simulation in the retention of ACLS knowledge. Resuscitation 2011;82:1440-3.

34. Ray SM, Wylie DR, Shaun Rowe A, Heidel E, Franks AS. Pharmacy student knowledge retention after completing either a simulated or written patient case. Am J Pharm Educ 2012; 76:86

35. Ten Eyck RP, Tews M, Ballester JM. Improved medical student satisfaction and test performance with a simulation-based emergency medicine curriculum: a randomized controlled trial. Ann Emerg Med 2009; 54:684-91.

36. Crotty BJ. More students and less patients: the squeeze on medical teaching resources. Med J Aust 2005; 183:444-5.

37. Zigmont JJ, Kappus LJ, Sudikoff SN. Theoretical foundations of learning through simulation. Semin Perinatol 2011; 35:47-51.

38. Annis LF. The processes and effects of peer tutoring. Hum Learn J Pract Res Appl 1983; 2:39-47.

39. Chandratilake M, McAleer S, Gibson J. Cultural similarities and differences in medical professionalism: a multi-region study. Med Educ 2012; 46:257-66.

40. Sethuraman KR. Professionalism in medicine. Regional Health Forum 2006; 10:1-10. Available at: https://pdfs.semanticscholar.org/3639/757741 aea 29f165fb1523207d43253cce144.pdf. Accessed May 25, 2017. 


\section{APPENDIX 1}

\section{Design of simulation sessions}

\section{Conceptualisation by Year 2 residents}

Year 2 residents identify a list of acute clinical scenarios commonly encountered by junior residents.

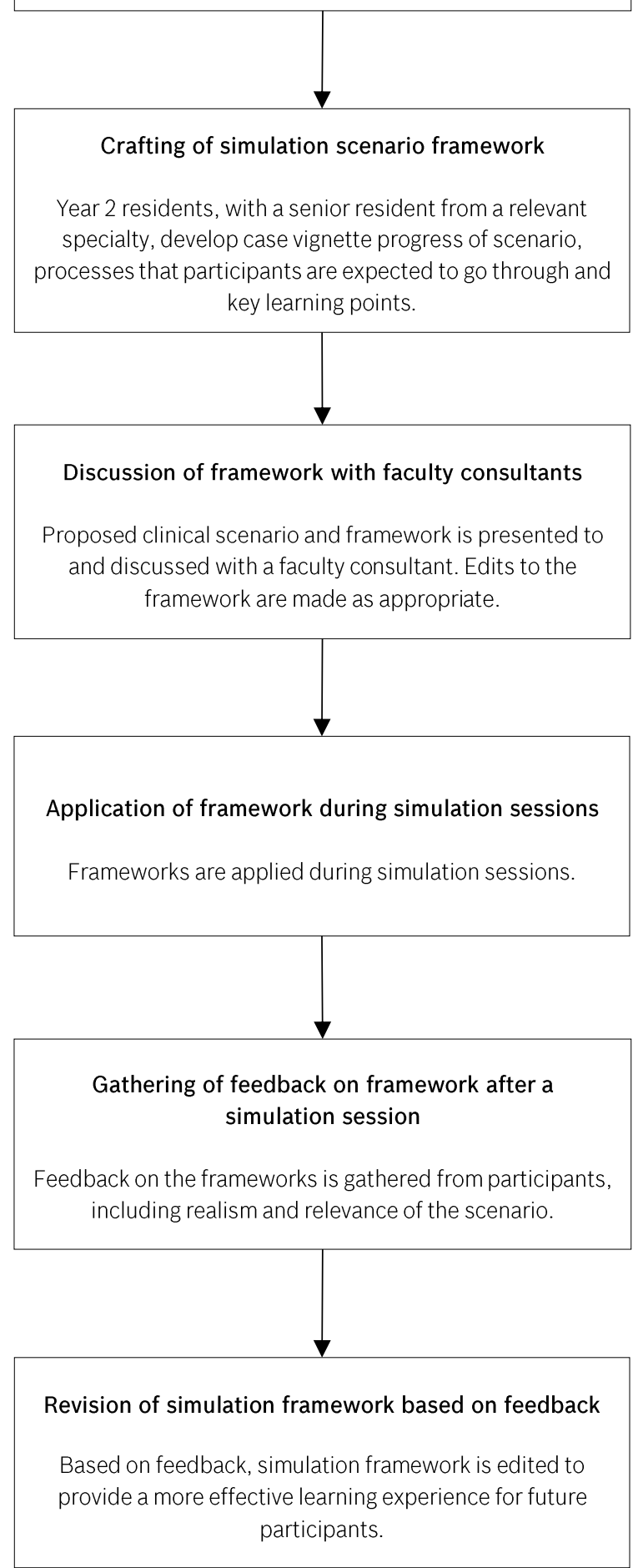




\section{APPENDIX 2}

\section{Conduct of simulation sessions}

\section{Introduction}

Year 2 residents begin with an introduction to the simulation scenario in the form of a case vignette.

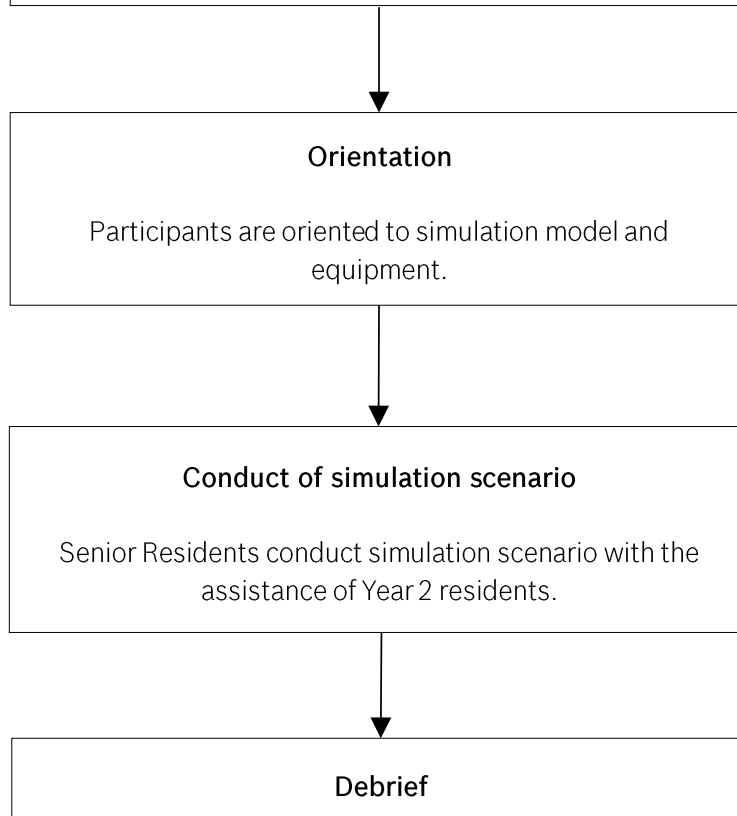

Senior Residents lead a debrief for all participants, focusing on self and peer reflection. Year 2 residents supplement observations and learning points.

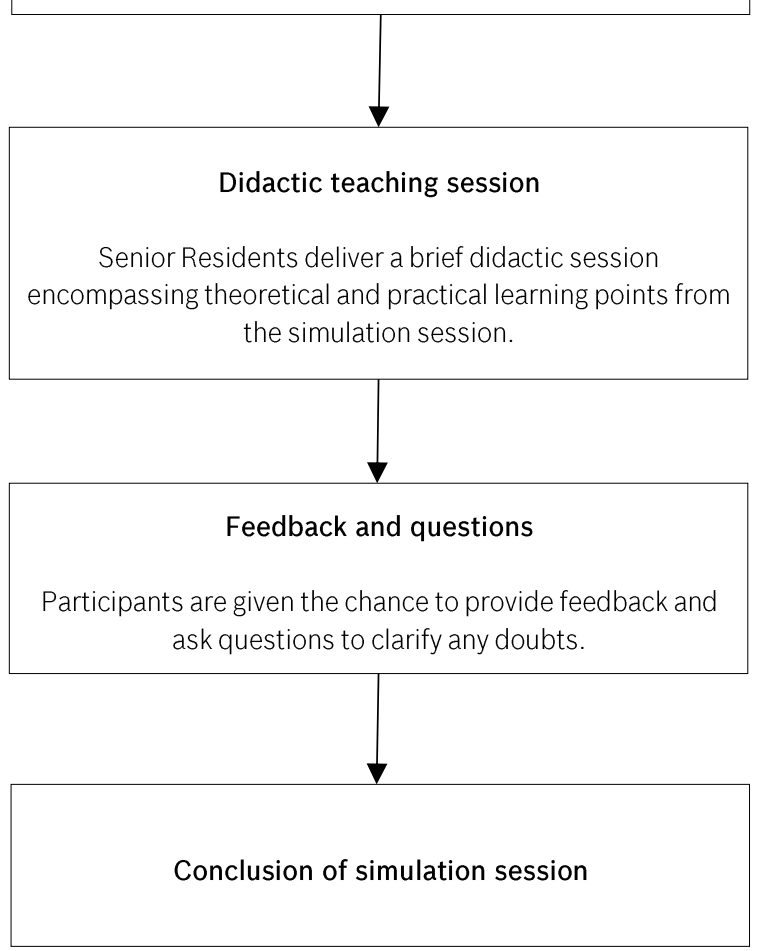




\section{APPENDIX 3}

\section{(a) Pre-simulation feedback}

Study code:

PGY: Year of graduation:

Gender:

Age:

Medical School:

IM Resident/HOPEX/Other Residency (Please specify):

Months of experience in Internal Medicine:

(1) Have you ever undergone simulation teaching before?
$\square \quad$ Yes
$\square$ No

(2) Briefly describe how you would recognise a critically ill patient:

(3) How would you describe your level of knowledge associated with recognising a critically ill patient? (Please circle the appropriate response)

No Knowledge
Nonsiderable Knowledge

(4) How would you describe your level of experience associated with recognising a critically ill patient? (Please circle the appropriate response)

1---------2---------3----------4---------5----------6---------7---------8---------9---------10

No Experience Considerable Experience

(5) Briefly describe any worries or concerns you have about recognising a critically ill patient.

(6) On a scale of 1-10, how confident are you that you are able to: (Please circle the appropriate response)

(a) Recognise a critically ill patient

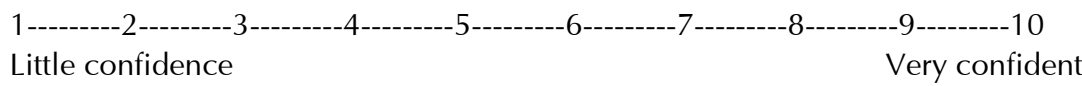

(b) Keep a patient alive until appropriate help arrives

1---------2---------3---------4---------5---------6---------7---------8---------9---------10

Little confidence Very confident

(c) Remember all essential lifesaving procedures when working with a critically ill patient

1-------2--------3---------4--------5--------6-------7-------8-------9-------10
Little confidence

(7) From the list below, tick 5 items that give you the most concern when dealing with a critically ill patient. Rank your 5 items that give you the most concern when dealing with a critically ill patient. Rank your 5 items in order of concern by placing a number in the adjacent box. $(1=$ most concern; $5=$ least concern. $)$ Do not have any shared ranks. Leave remaining boxes blank.

Lack of diagnosis

Rapid deterioration

Lack of prior specific experience

Keeping calm

Remembering to conduct all appropriate investigations

Applying skills in real life setting 
Lack of competence

_ Unable to get help when needed

Taking too long to react

_ Finding specific procedure/ actions difficult

Lack of knowledge

(8) Please comment on how worried you are about the prospect of being responsible for critically ill patients.

(9) Please indicate on your level of agreement with the following statements. These statements only refer to situations where you are working with critically ill patients and not any other contexts. (Please circle the appropriate response)

(a) I feel more confident when working as a part of a multidisciplinary team

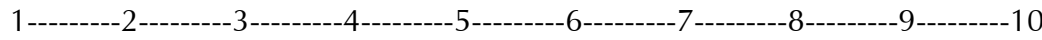

Strongly disagree $\quad$ Strongly agree

(b) Working in a multidisciplinary team would make me feel anxious

1---------2---------3----------4---------5---------6---------7---------8---------9---------10

Strongly disagree $\quad$ Strongly agree

(c) I feel more at ease working as part of a team of individuals from my own profession

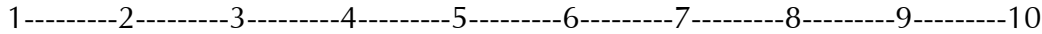

Strongly disagree $\quad$ Strongly agree

(d) I prefer to work with people from my own profession as it improves efficiency

1---------2---------3---------4---------5---------6---------7---------8---------9---------10

Strongly disagree $\quad$ Strongly agree

(e) I find that cooperation with individuals from other professions is fraught with difficulty

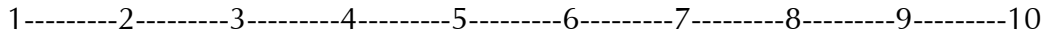

Strongly disagree $\quad$ Strongly agree

(f) I like to collaborate with other professionals

1---------2---------3---------4---------5---------6---------7---------8---------9---------10

Strongly disagree $\quad$ Strongly Agree

\section{(b) Post-simulation feedback}

Study Code:

PGY: ___ Year of graduation: ___ Gender: ____ Age:

Medical School:

IM Resident/HOPEX/Other Residency (Please specify):

Months of experience in Internal Medicine: 
(1) Post simulation, briefly describe how you would recognise a critically ill patient.

(2) Post simulation, how would you describe your level of knowledge associated with recognising a critically ill patient? (Please circle the appropriate response)

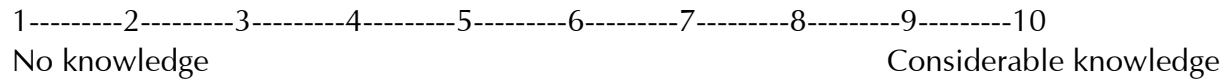

(3) Post simulation, how would you describe your level of experience associated with recognising a critically ill patient?

1---------2---------3---------4---------5---------6---------7---------8---------9---------10

No experience Considerable experience

(4) Post simulation, briefly describe any worries or concerns you have about recognising a critically ill patient.

(5) Post simulation, on a scale of 1-10, how confident are you that you are able to: (Please circle the appropriate response)

(a) Recognise a critically ill patient

1--------2--------3---------4---------5---------6--------7---------8--------9--------10

Little confidence Very confident

(b) Keep a patient alive until appropriate help arrives

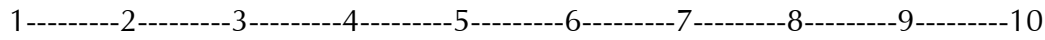

Little confidence Very confident

(c) Remember all essential lifesaving procedures when working with a critically ill patient

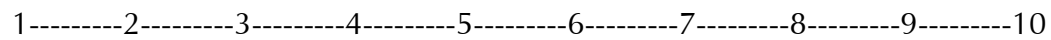

Little confidence Very confident

(6) From the list below, rank 5 items that Simulation has been most useful in helping you to deal with a critically ill patient. Rank your 5 items in order of $1=$ most useful and $5=$ least useful. Do not have any shared ranks. Leave remaining spaces blank.

L Lack of diagnosis

Rapid deterioration

Lack of prior specific experience

Keeping calm

Remembering to conduct all appropriate investigations

Applying skills in real life setting

Lack of competence

Unable to get help when needed

_ Taking too long to react

Finding specific procedure/ actions difficult

__ Lack of knowledge 
(7) Post simulation, please comment on how worried you are about the prospect of being responsible for critically ill patients.

(8) Please kindly grade the effectiveness of the individual simulation sessions. Please circle the appropriate response. Circle NA if you did not attend the session.

(a) Bleeding gastrointestinal tract

1---------2---------3---------4---------5---------6---------7---------8--------9---------10 $\quad$ NA
Least effective

(b) Acute myocardial infarction and complications

1---------2---------3---------4---------5---------6---------7---------8---------9---------10 N NA

Least effective $\quad$ Most effective

(c) Severe pneumonia

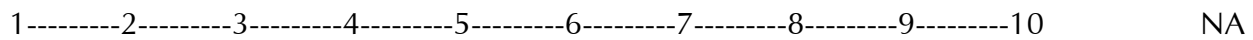

Least effective $\quad$ Most effective

(d) Transfusion associated lung injury (TRALI)

1---------2---------3---------4----------5---------6--------7---------8---------9---------10 NA

Least effective Most effective

(e) Atrial fibrillation and complications

1--------2--------3--------4--------5-------6-------7-------8--------9-------10 NA

Least effective Most effective

Simulation training

On a scale of 1-5: 1 being "Strongly Disagree", 2 being "Disagree", 3 being "Neutral", 4 being "Agree" and 5 being "Strongly Agree", please tick the appropriate box.

\begin{tabular}{|c|c|c|c|c|c|}
\hline & 1 & 2 & 3 & 4 & 5 \\
\hline $\begin{array}{l}\text { Simulation is an accurate reflection of medical } \\
\text { emergencies faced in my daily clinical work }\end{array}$ & & & & & \\
\hline The simulation was a valuable learning experience & & & & & \\
\hline I prefer Simulation training over didactic sessions & & & & & \\
\hline Simulation training should be done after didactic sessions & & & & & \\
\hline $\begin{array}{l}\text { Simulation should be conducted earlier in the year (Please } \\
\text { indicate in comment session which quarter of your PGY1 } \\
\text { you would have liked Simulation Training to have been } \\
\text { conducted) }\end{array}$ & & & & & \\
\hline $\begin{array}{l}\text { Given the chance, I would like to have been actively } \\
\text { involved in all the Simulation scenarios }\end{array}$ & & & & & \\
\hline $\begin{array}{l}\text { The number of Simulation Scenarios is just right } \\
\text { (If disagree/strongly disagree, kindly indicate in the } \\
\text { comments section how many stations you will have } \\
\text { preferred for Simulation Training as well as the stations } \\
\text { you will like to include for Simulation Training) }\end{array}$ & & & & & \\
\hline
\end{tabular}




\begin{tabular}{|l|l|l|l|l|l|}
\hline $\begin{array}{l}\text { I will have preferred a dedicated day for all the Simulation } \\
\text { training to be conducted as opposed to having it spread } \\
\text { over multiple weeks }\end{array}$ & & & & & \\
\hline $\begin{array}{l}\text { I would be keen to help the next batch of HOs plan their } \\
\text { simulation training the following year }\end{array}$ & & & & & \\
\hline
\end{tabular}

Other comments:

\section{Timing of Simulation Session}

Simulation: 10-15 minutes

Debriefing and education of learning points: 30 minutes

Feedback and didactic add on points: 10-15 minutes

On a scale of 1-3: 1 being "Too Short", 2 being "Just Right", 3 being "Too Long", please tick the appropriate box.

\begin{tabular}{|l|l|l|l|}
\hline & 1 & 2 & 3 \\
\hline The timing allocated for the simulation session was & & & \\
\hline The timing allocated for the debriefing session was & & & \\
\hline The timing allocated for the didactic session was & & & \\
\hline
\end{tabular}

Other comments: 